\title{
Structural Design Of Driving System For Anti-Terrorism Robot
}

\author{
WANG Yong ${ }^{1, a}$, XING Jin-Peng ${ }^{2, b^{*}}, X U$ Yan $^{1, c}$ and HU Bin ${ }^{1, d}$ \\ ${ }^{1}$ Shanghai Fire Research Institute of Ministry of Public Security, Shanghai 200438,China \\ ${ }^{2}$ Department of Mechanical and Electronic Engineering, Dongchang College of Liaocheng University, \\ Shandong Liaocheng 252000,China \\ aemail:wangecust@163.com, ${ }^{b}$ email:XJP@qq.com, ${ }^{\mathrm{c} e m a i l: y x @ 163 . c o m, ~}{ }^{\mathrm{d}}$ email:bh@163.com \\ * corresponding author
}

Keywords: Mobile drive system, Anti-terrorism robot, Mechanical structural design, Explosion proof technology design, Power calculation

\begin{abstract}
The mobile drive system is an very important part of the robot, and the structural design of drive system for anti-terrorism robot will be discussed in this paper. The structural design of drive system mainly include: mechanical structure design, explosion proof technology design and power calculation. We will make a detail analysis for the above content and the experimental results show that the proposed structural design of driving system can meet the driving requirement of our designed anti-terrorism robot.
\end{abstract}

\section{Introduction}

In recent years, frequent occurrence of the public safety incidents home and abroad. How to stop the riots, terrorism and maintain social security effectively, which has got a great concern for the relevant departments of all countries[1-4]. Usually in the event of a riot, special weapons and tactics (SWAT) fighters tend to rush in front of the danger. But at that monument, their life of SWAT fighters will be in great threat. Fortunately, with the development of robotics, there are many countries research and developed many different kinds anti-terrorism robots to assist the SWAT fighters to deal with the riots.

Many research institutes and research companies of United States has made a lot of effort on anti-terrorism robot after the 9.11 terrorist attacks[5-7]. Japan has advanced robotics technology and R\&D experiences. Rescue and anti-terrorism robots with multiple different functions are available in Japan after many years of research[8-9]. China as the biggest development country in the world, develop suitable anti-terrorism robots for domestic must be done at this moment. Shanghai fire research institute of ministry of public security and Shenyang institute of automation of Chinese academy of sciences have done a lot of related research work on anti-terrorism robots[10-12]. However, no matter what kind of functions the anti-terrorism or rescue robots has, running reliable and flexible driving system is a prerequisite to achieve these functions.

In this paper, the detail of structural design of driving system will be introduced. The structural design of drive system mainly include: mechanical structure design, explosion proof technology design and power calculation. Later, we will analyse those contents respectively. The structure of this paper is arranged as follows. In section 2,the mechanical structure design and the explosion proof technology design will be introduced. The power calculation will be shown in section 3 . Finally, the conclusions will be given in Section 4.

\section{The Mechanical Structure Design}

The mechanical structure design of anti-terrorism robot, which is an important part of the research on the robot. The mechanical structure of anti-terrorism robot is independent of the other auxiliary system (control system, sensor system ). Meanwhile, whether the mechanical structure design of the robot is reasonable or not, and it directly related to the functional integrity of the other auxiliary 
system. According to the requirements of the anti-terrorism robot, the mechanical structure of the robot mainly include: cabin, anti rotation arm, walking side panel, caterpillar and son on. The schematic diagram of mechanical structure of anti-terrorism robot can be found in fig 1 . The technical parameters of this mechanical structure of anti-terrorism robot were listed in table 1.

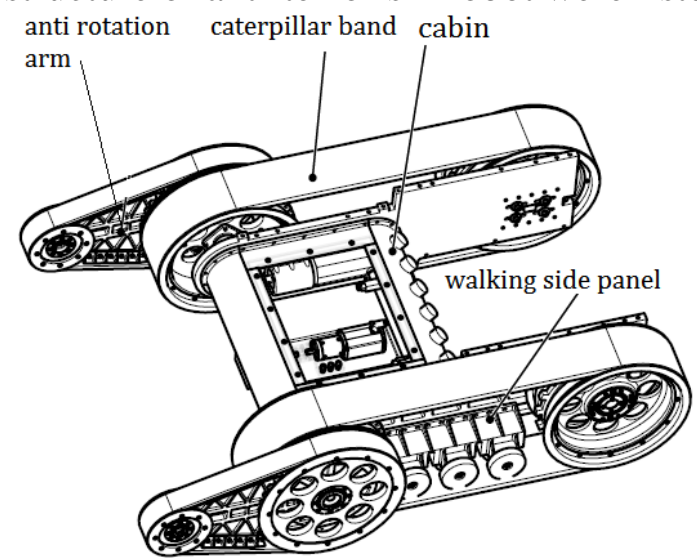

Fig. 1 The schematic diagram of mechanical structure of driving system for anti-terrorism robot

Table 1 Main technical performance parameters of mechanical structure of anti-terrorism robot

\begin{tabular}{cc}
\hline Project & Parameters \\
\hline Weight $/ \mathrm{kg}$ & $\leq 180$ \\
walking speed $/(\mathrm{km} / \mathrm{h})$ & $\geq 4$ (adjustable) \\
Load $/ \mathrm{kg}$ & $\leq 70$ \\
The height of obstacle crossing & $\leq 250$ \\
$/ \mathrm{mm}$ & 30 \\
Climbing $/\left({ }^{\circ}\right)$ & 2 \\
Duration of work $/ \mathrm{h}$ & $-5 \sim 55$ \\
Working temperature $/\left({ }^{\circ} \mathrm{C}\right)$ & \\
\hline
\end{tabular}

The Choice Of Mobile Device. The designed anti-terrorism robot will work in a complex environment, such as slope, gully, ladder, et al. Available mobile devices for anti-terrorism robot mainly include: wheel, caterpillar and multi-foot three kinds. The characteristics of the above three types of mobile device for anti-terrorism robot are summarized in table 2.

Table 2 Comparison of different mobile devices for anti-terrorism robot

\begin{tabular}{|c|c|c|c|}
\hline Category & Type & Advantages & Disadvantages \\
\hline wheel & $\begin{array}{l}3 \text { wheels } \\
4 \text { wheels } \\
5 \text { wheels } \\
6 \text { wheels }\end{array}$ & $\begin{array}{l}\text { Simple structure, light weight, small } \\
\text { friction resistance, high mechanical } \\
\text { efficiency }\end{array}$ & $\begin{array}{l}\text { poor adhesion between wheels and } \\
\text { ground, poor cross-country } \\
\text { performance }\end{array}$ \\
\hline caterpillar & $\begin{array}{l}2 \text { caterpillars } \\
4 \text { caterpillars } \\
6 \text { caterpillars }\end{array}$ & $\begin{array}{l}\text { Obstacle crossing ability, stair } \\
\text { climbing, trenches, threshold and } \\
\text { other obstacles }\end{array}$ & $\begin{array}{l}\text { complex structure, large weight, } \\
\text { high friction resistance, low } \\
\text { mechanical efficiency }\end{array}$ \\
\hline Multi-foot & $\begin{array}{l}4 \text { foot } \\
4 \text { foot } \\
6 \text { foot } \\
8 \text { foot }\end{array}$ & powerful obstacle crossing ability & $\begin{array}{c}\text { complex structure, low mechanical } \\
\text { efficiency }\end{array}$ \\
\hline
\end{tabular}

From table 2 we can find that each mobile device has its suitable occasion, and there is no one kind of mobile device can meet all requirements. Due to our designed anti-terrorism robot mainly work in complex environment, and from mechanical design and practical application point of view, by comparing the three different mobile devices, we can know that the caterpillar might be the best choice. In addition, in order to improve the obstacle crossing ability of current mobile device using caterpillar effectively. We added two forearms (anti rotation arm) in each side of the two walking side panels (Fig.1).

The Explosion Proof Structure Design. The designed anti-terrorism robot might work in harsh environment, such as high temperature, humidity, corrosion and so on. In addition, in the process of using anti-terrorism robot, there are electrical sparks and mechanical friction, and sometimes there may appear arcing and overheating. If no specific measure deal with the problems mentioned above, 
that may lead to major accidents[13]. We will design the following several aspects: mechanical spark prevention, static prevention, drive/brake system, cable and installation, electrical protection and waterproof structure design to achieve explosion proof function.

Mechanical Spark Prevention. Under normal operating conditions, the anti-terrorism robot might occur friction or collision with the external, which might cause mechanical spark on the outer surface of the robot. In order to eliminate the mechanical spark, we utilize copper, copper zinc alloy, copper beryllium alloy, stainless steel and other materials or use non-metallic materials to cover the possible position of the anti-terrorism robot that might occur collision.

Static Prevention. The following parts easy to generate and accumulate electrostatic charges, such as caterpillar, polymer material idler pulley ,driven wheel and drive pulley. In order to prevent the generation and accumulation of electrostatic charge, we adopt the following anti-static measures.

(1)Add appropriate conductive agent in caterpillar to achieve anti-static.

(2)Measure the sheet resistance of caterpillar and to ensure the sheet resistance of utilized material not exceeding $109 \Omega$ (relative humidity 50\%) or not exceeding $1011 \Omega$ (relative humidity 30\%).

(3)All metal parts are connected to the frame to maintain the potential balance of all the components on the anti-terrorism robot.

Drive/Brake System. The drive / brake system of the anti-terrorism robot is the moving carrier, and ensure all parts of it should be flexible and well lubricated. For all the metal parts in drive / brake system, we adopt the following requirements: (i) the content of magnesium, titanium, zirconium should not exceed 7.5\%, magnesium should not exceed 6\%;(ii) using solid lubricant for those metal parts exposed to the outside of the explosion cabin.

Cable And Installation. All the lines of anti-terrorism robot should use insulated copper cable, and the current-carrying capability of the cable should be guaranteed. When the rated current through the related electrical equipment of anti-terrorism robot, and the Induced temperature by current can not be higher than the allowable temperature of insulating materials. At the same time, the cable should withstand voltage test under the relevant voltage requirements. In addition, all cables must be far away from high temperature components and moving parts during installation..

Electrical Protection. Setting the current protection in the electrical circuit of the anti-terrorism robot, to prevent excessive current cause damage to the battery and cause high temperature.

Waterproof Structure Design. The application location of anti-terrorism robot is complicated and changeable, and inevitably encounter a water environment or encounter liquid attack. So, the waterproof function is very necessary for our designed anti-terrorism robot.

we adopt the following measures to achieve waterproof function:(i) in connecting part of front cabin and the left and right side plates, we added a sealing groove seal placed in the front cabin body, and fastening the front cabin between the left and right side plate by the inner six angle screw. (ii) in the connection area of the upside of front cabin and the loam cake, added a sealing groove seal placed in the upside of loam cake. The schematic diagram of sealing position can be found in fig 2 .

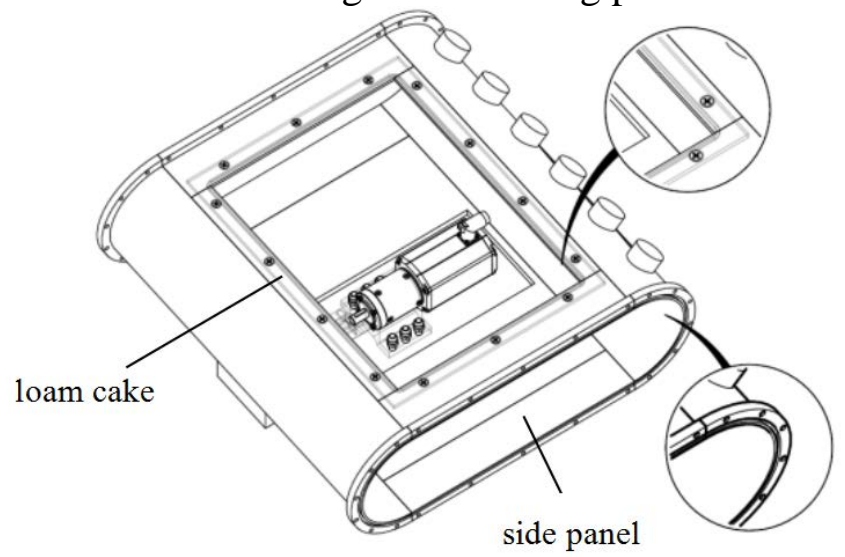

Fig. 2 The schematic diagram of sealing position for loam cake and side panels 


\section{The Power Calculation}

The method of quasi limit design method[14] was chosen to calculate the power of the anti-terrorism robot. The core idea of the quasi limit design method is that fully use the overload capacity of motor, reducer and other standard parts, so that those standard parts can be as small as possible, and to achieve the purpose of reducing the size and weight of the robot. In the part of power calculation, using quasi limit design method the static analysis, force analysis for 30o slope, obstacle height analysis and climbing steps analysis for the anti-terrorism robot will be analyzed respectively.

The Static Analysis. The anti-terrorism robot was driven by two motors, and to drive a robot parked on a horizontal plane using theoretical mechanics analysis we can find the following result. Figure 3 is the force analysis of robot on a horizontal plane.

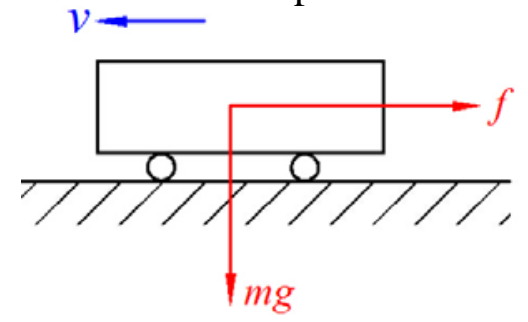

Fig. 3 The schematic diagram of force analysis of robot on a horizontal plane

$$
f=\mu m g
$$

Where is the friction, is the weight of robot, is the gravity coefficient, is the moving direction of robot. If the anti-terrorism robot wants to move in a static state, the traction force of a single motor is at least greater than or equal to $f / 2$.

The Force Analysis For $30^{\circ}$ Slope. The designed anti-terrorism robot have ability of climbing $30^{\circ}$ slope. Figure 4 shows the force analysis of robot climbing $30^{\circ}$ slope.

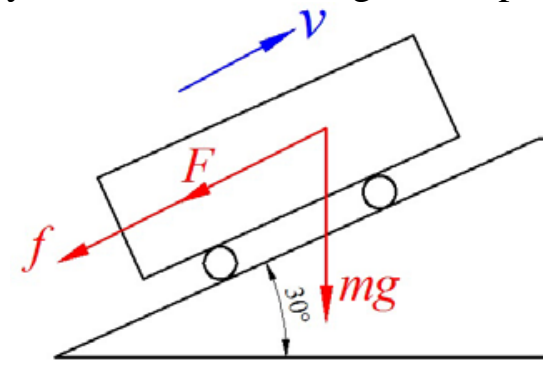

Fig. 4 The schematic diagram of force analysis of robot climbing $30^{\circ}$ slope

$$
\begin{aligned}
& F=m g \times \sin 30 \\
& f=\mu m g \times \cos 30
\end{aligned}
$$

Where $f$ is the friction, $F$ is the component of force of gravity, and only the traction force of a single motor up to $(f+F) / 2$ can the robot climb $30^{\circ}$ slope.

Obstacle Height Analysis. If the anti-terrorism robot will cross height obstacle, and establish coordinate system as shown in Figure 5. From figure 5 we can know the length of anti rotation arm of robot.

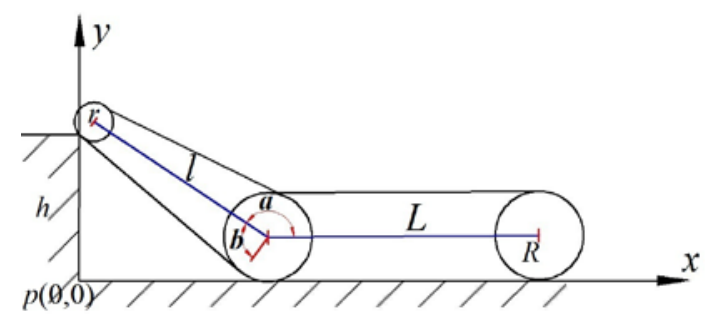

$l=h+r \sin (b-a)$

Fig. 5 The schematic diagram of obstacle height analysis 
In the process of crossing $h$ height obstacle, the force and deformation analysis for anti rotation arm of robot is very necessary. Given the anti rotation arm of robot unilateral $2000 \mathrm{~N}$ loading and the material is carbon steel, thickness is $6 \mathrm{~mm}$.

The schematic diagram of cross obstacle for anti-terrorism robot is shown as figure 6 .

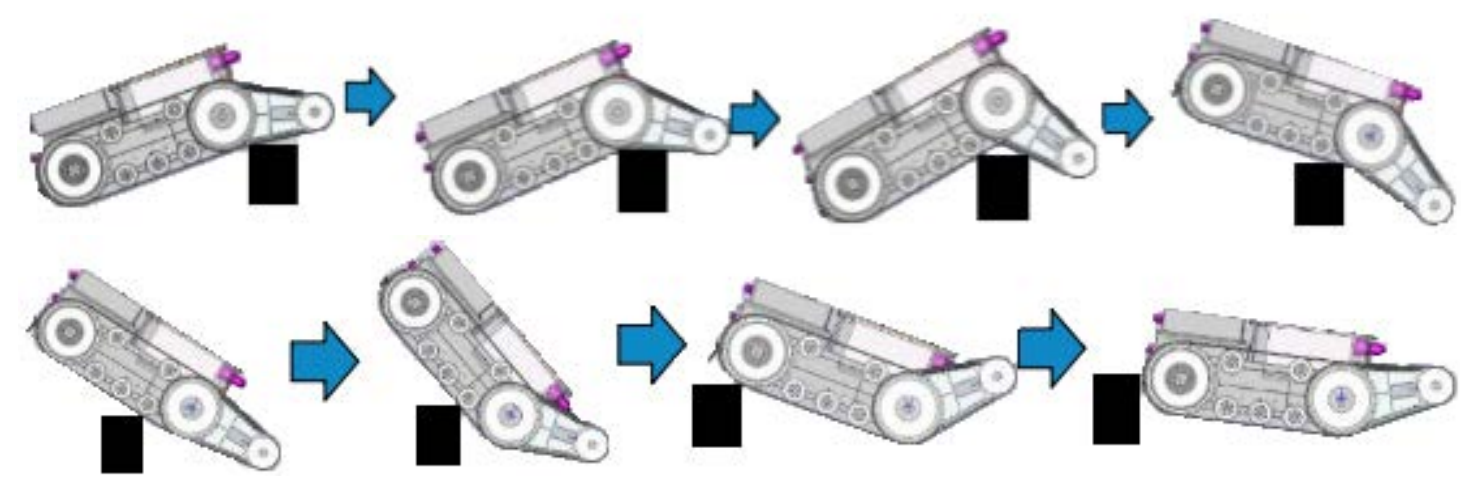

Fig. 6 The schematic diagram of cross obstacle for anti-terrorism robot

\section{Summary}

The mechanical structure design of driving system for anti-terrorism robot include: the choice of mobile device, and the explosion proof structure design ( mechanical spark prevention, static prevention, drive/brake system, cable and installation, electrical protection and waterproof structure design) were discussed respectively.

In the part of power calculation,the method of quasi limit design was utilized to analyse four aspects: the static analysis, force analysis for $30^{\circ}$ slope, obstacle height analysis and climbing steps analysis for the anti-terrorism robot.

\section{Acknowledgement}

The research was sponsored by Shanghai Science and Technology Commission ( No. 14dz1206802)

\section{References}

[1] J.G.Liu, Y.C.Wang, B.Li, et al. Current research, key performances and future development of search and rescue robot, Frontiers of Mechanical Engineering in China. 2(2007) 401-416.

[2] E.Goetz. Violence prevention and beyond-Theses on the spirit of terrorism, Egyptian Journal of Forensic Sciences. 5(2015)75-81.

[3] S.A.Ahmed. Development of Kinematic Path-Tracking Controller Design for Real Mobile Robot via Back-Stepping Slice Genetic Robust Algorithm Technique, Arab J Sci Eng. 39(2014) 8825-8835.

[4] B.B.V.L.Deepak, R.Dayal, B.M.V.A. Parhi .Advance Particle Swarm Optimization-Based Navigational Controller For Mobile Robot, Arab J Sci Eng. 39(2014)6477-6487.

[5] A. Larson, R. Voyles. TerminatorBot:a novel robot with dual-use mechanism for locomotion and manipulation, IEEE-ASME T Mech.10(2005)17-25.

[6] Z.X.Yang, K.Ito, K.Saijo, et al. A rescue robot for collecting information designed for ease of use, Adv Robotics.19(2005)249-272.

[7] Y.Yuguchi, Y.Satoh. Development of a robotic system for nuclear facility emergency preparedness-observing and work-assisting robot system, Adv Robotics.16(2002)481-484.

[8] Y.Wang, J.P.Xing, H.Guo,et al. Key technologies of tunnel firefighting robot. IETE Technology Review,doi:10.1080/02564602.2016.1139475,(2016). 
[9] J.G.Liu, Y.C.Wang, B.Li, et al. Link-type shape shifting modular robot for search and rescue, H Tech Let.10(2004)179-183.

[10]J.G.Liu, Y.C.Wang, B.Li, et al.. Analysis of tipover stability for novel shape shifting modular robot, Chin J Mech Eng.19(2006)187-192.

[11]X.W.Rong, R.Song, X.M.Song, et al. Mechanism and explosion-proof design for a coal mine detection robot, Pro Eng.15(2011)100-104.

[12]L.Jesusu, M.Vicente,C.Maria. Nistal. Designing of monomode step-index channel guides with quasi-exact modal solutions by the effective index method, J Mod Optic.47(2000)599-604. 